\title{
PERLINDUNGAN KREDITUR PENERIMA FIDUSIA ATAS MUSNAHNYA BENDA YANG MENJADI OBYEK JAMINAN*
}

\author{
Oleh : \\ Luh Gede Pebby Gitasari** \\ I Made Udiana ${ }^{* * *}$ \\ I Nyoman Mudana**** \\ Bagian Hukum Bisnis \\ Fakultas Hukum Universitas Udayana
}

\begin{abstract}
ABSTRAK
Jaminan Fidusia berperan penting dalam menjamin hak dari kreditur yang memberikan pinjaman kepada debitur.Jika dilihat dalam pada Pasal 25 Undang-Undang Nomor 42 Tahun 1999 Tentang Jaminan Fidusia, disana terdapat ketidak jelasan atas pengaturan tentang musnahnya benda yang menjadi obyek jaminan atau adanya kekaburan hukum tentang pengertian musnah dalam pasal tersebut.Permasalah yang diteliti dalam penulisan yaitu tentang pengaturan perlindungan kreditur penerima fidusia atas musnahnya benda yang menjadi obyek jaminan dan upaya yang dapat dilakukan oleh kreditur penerima fidusia untuk pelunasan piutang akibat musnahnya benda yang menjadi obyek jaminan.
\end{abstract}

Metode penelitian yang digunakan adalah metode penelitian normatif, adalah penelitian yang didasarkan kepada data sekunder. Penelitian hukum mempergunakann pendekatan perundang-undangan (Statute Approach) dan mepergunakan pendekatan analisis (Analytical Approach).

\footnotetext{
" Penulisan karya ilmiah yang berjudul Perlindungan Kreditur Jaminan Fidusia Atas Musnahnya Benda yang Menjadi Obyek Jaminan, ini adalah ringkasan dari skripsi.

"* Penulis pertama didalam penulisan dibuat Luh Gede Pebby Gitasari, selaku mahasiswa Fakultas Hukum Universitas Udayana.

"* Penulis kedua didalam penulisan dibuat Dr.I Made Udiana,SH.,M.H selaku Pembimbing Pertama Skripsi merupakan penulis kedua di Fakultas Hukum Universitas Udayana.

*** Penulis ketiga didalam penulisan dibuat I Nyoman Mudana, $\mathrm{SH}, \mathrm{MH}$ selaku Pembimbing Kedua merupakan penulis ketiga di Fakultas Hukum Universitas Udayana.
} 
Berdasarkan Pasal 15 ayat 3 Undang-Undang Nomor 42 Tahun 1999 Tentang Jaminan Fidusia "Apabila debitor cidera janji, Penerima Fidusia mempunyai hak untuk menjual Benda yang menjadi objek Jaminan Fidusia atas kekuasaannya sendiri". Kreditur memiliki hak didalam perjanjian yang dibuat, dimana haknya adalah untuk menuntut perusahaan asuransi untuk mencairkan uang asuransi yang dimana hal ini untuk menutup kerugian dari objek jaminan fidusia yang musnah yang diakibatkan karena kesalahan dari debitur yang sesuai ketentuan yang terdapat di dalam perjanjian asuransi untuk melindungi kepentingan kreditur.Upaya yang dapat dilakukan dengan cara pembaruan utang dengan mengganti utang lama dengan utang baru, dimana yang diganti disini perjanjian kreditnya dengan perjanjian kredit yang baru. Musnahnya benda yang menjadi objek jaminan karena kesengajaan dilakukan debitur maka pihak kreditur dapat menuntut pergantian atas benda jaminan tersebut dengan nilai jaminan yang sama, namun apabila dari pihak debitur tidak merespon atau menanggapi, maka pihak Kreditur dapat menempuh jalur hukum dengan cara litigasi maupun no litigasi.

\section{Kata Kunci : Perlindungan Hukum, Jaminan Fidusia, Musnahnya Jaminan Fidusia}

\section{ABSTRACT}

Fiduciary guarantees play an important role in guaranteeing the rights of creditors who provide loans to debtors. If seen in Article 25 of Law Number 42 of 1999 concerning Fiduciary Guarantees, there is a lack of clarity on the regulation regarding the destruction of objects which are objects of guarantee or the existence of legal obscurity regarding understanding destroyed in the article. The problems examined in writing are about regulating the protection of a fiduciary recipient's creditors for the destruction of objects that are objects of guarantee and efforts that can be made by the fiduciary recipient's creditors to repay the debts due to the destruction of objects that are guaranteed objects.

The research method used is a normative research method, is research that is based on secondary data. Legal research uses the Statute Approach and uses Analytical Approach. 
Based on Law Number 42 of 1999 concerning Fiduciary Guarantees the creditor has the right to claim compensation to the debtor. The creditor has the right in the agreement, his right to sue the insurance company to withdraw the insurance money which is to cover the loss of the fiduciary collateral object which was destroyed due to errors from the debtor in accordance with the provisions contained in the insurance agreement to protect the interests of creditors. which can be done by means of debt renewal by replacing the old debt with new debt, which is replaced here with the new credit agreement. The disappearance of objects that are objects of guarantee because of the intentions of the debtor, the creditor can demand a replacement for the collateral object with the same collateral value, but if the debtor does not respond or respond, the creditor can take legal action by litigation and litigation no.

\section{Keywords: Legal Protection, Fiduciary Security, Loss of Fiduciary Security}

\section{PENDAHULUAN}

\subsection{Latar belakang}

Bank yaitu badan usaha di bidang perekonomian yang dibuat oleh pemerintah yang bertujuan untuk menghimpun dana dan menyalurkan dana kepada masyarakat dan memajukan perekonomian. Berdasarkan Pasal 1 angka 2 Undang-Undang Nomor 10 Tahun 1998 Tentang Perubahan Atas Undang-Undang Nomor 7 Tahun 1992 Tetang Perbankan menjelaskan bahwa Bank adalah badan usaha yang menghimpun dana dari masyarakat dalam bentuk simpanan dan menyalurkannya kepada masyarakat dalam bentuk kredit dan atau bentuk-bentuk lainnya dalam rangka meningkatkan taraf hidup rakyat banyak".

Menurut O.P. Simorangkir, Bank yaitu salah satu badan usaha lembaga keuangan yang bertujuan memberikan kredit dan jasa. Pemberian kredit dilakukan baik dengan modal sendiri ataupun dengan dana yang dipercayakan oleh 
pihak ketiga maupun dengan jalan mengedarkan alat-alat pembayaran baru berupa uang. ${ }^{1}$ Bank sering menggunakan perjanjian kredit, perjanjian kredit tersebut dilakukan oleh pihak bank yang akan memberikan jaminan kepada nasabahnya berupa barang atau bendayang ingin mengajukan kredit kepada pihak bank selaku kreditur. Perjanjian kredit disini berisi tentang pengaturan tentang hak dan kewajiban antara kreditur maupun debitur yang membuat perjanjian tersebut sehubungan dengan pemberian kredit yang akan diajukan oleh nasabahnya.

Fidusia dalam Bahasa Indonesia disebut juga dengan istilah "Penyerahan Hak Milik Secara Kepercayaan"2. Musnahnya benda yang menjadi jaminan biasanya disebabkan karena terjadinya pencurian, kebakaran, bencana alam, dan lain-lain. Benda yang menjadi obyek jaminan itu musnah diatur dalam Pasal 25 Undang-Undang Nomor 42 Tahun 1999 Tentang Jaminan Fidusia.

Jika mengkaji Pasal 25 Undang-Undang Nomor 42 Tahun 1999 Tentang Jaminan Fidusia, maka di dalam pasal tersebut tidak jelasnya pengaturan tentang musnahnya benda yang menjadi obyek jaminan atau adanya kekaburan hukum dan juga terjadi ketidak jelasan tentang perlindungan hukum bagi pihak kreditur atas musnahnya benda yang menjadi obyek jaminan terutama di dalam pendaftaran fidusia yang akan di lakukan oleh pihak bank karena di dalam pendaftran jaminan fidusia hanya sampai pendaftaran di kantor jaminan fidusia saja.

Selain itu, tidak jelas upaya yang dapat dilakukan oleh kreditur penerima fidusia untuk pelunasan piutang akibat

\footnotetext{
${ }^{1}$ O. P. Simorangkir, 1998, Seluk Beluk Bank Komersial, Aksara Persada Indonesia, Jakarta, h.10.

${ }^{2}$ Munir Fuady, 2003, Jaminan Fidusia, Citra Aditya Bakti, Cetakan ke-2 Revisi, Bandung, h. 3.
} 
musnahnya benda yang menjadi obyek jaminan yang berada di pihak nasabah selaku pihak debitur. Sesuai dengan uraian yang dijelaskan di atas maka dilakukan penelitian yang berjudul "Perlindungan Kreditur Penerima Fidusia Atas Musnahnya Benda Yang Menjadi Obyek Jaminan"

\subsection{Tujuan Penelitian}

Tujuan dari penelitian ini adalah untuk mengetahui dan memahami Perlindungan Kreditur Penerima Fidusia Atas Musnahnya Benda Yang Menjadi Obyek Jaminan.

\section{ISI MAKALAH}

\subsection{Metode Penulisan}

Penelitian ini mengacu pada rumusan masalah, maka menggunakan penelitian yang akan dipergunakan didalam penelitian hukum ini adalah penelitian hukum normatif. Penelitian hukum normatif yang sering juga disebut sebagai peneltian kualitatif. ${ }^{3}$

\subsection{Hasil dan Pembahasan}

\subsubsection{Pengaturan Perlindungan Kreditur Penerima Fidusia Atas Musnahnya Benda Yang Menjadi Obyek Jaminan}

Sebelum pemberian kredit dilakukan oleh pihak bank disini, pihak bank akan mempertimbangkan permohonan kredit yang akan di ajukan oleh calon nasabahnya. Dimana bank sebelum menyalurkan kredit kepada nasabahnya, terlebih dahulu pihak bank akan melakukan penyelidikan terhadap calon nasabahnya.

${ }^{3}$ Philipus M.Hadjon, Tatiek Sri Djatmiati, 2005, Argumentasi Hukum, Gajah Mada University Press, Yogyakarta, h. 1-2. 
Pemberi fidusia dapat lalai dan tdak bertanggung jawab atas kondisi benda persediaan yang dijaminkan yang mengakibatkan obyek jaminan rusak atau musnah. ${ }^{4}$

Semua bank yang ada di Indonesia pasti menggunakan perjanjian kredit, dimana perjanjian kredit disini dilakukan oleh pihak bank yang akan memberikan jaminan kepada nasabahnya. Pihak nasabah pasti akan diminta barang atau benda yang ingin di jaminkan kepada pihak bank guna untuk persyaratan di dalam mengajukan kredit kepada pihak bank selaku kreditur. Barang yang akan di jaminkan ini merupakan syarat utama di dalam pengajuan kredit bank selain kartu tanda penduduk (KTP), ataupun kartu keluarga (KK).

Unsur-unsur dari perjanjian kredit yang diberikan oleh pihak bank adalah 5C yaitu character, capacity, capital, condition, dan collateral. Unsur-unsur ini pasti akan di analisa oleh tim kredit dari bank yang bersangkutan agar kredit yang diberikan oleh bank tepat sasaran dan pihak bank tidak mengalami kerugian di kemudian hari.

Musnahnya benda yang menjadi obyek jaminan fidusia merupakan resiko lain yang timbul di dalam perjanjian jaminan. Musnah didalam kamus besar bahasa indonesia dapat di artikan lenyap. ${ }^{5}$ Musnahnya obyek jaminan dapat dibagi menjadi dua macam yaitu:

a) Musnahnya Secara Total (Seluruhnya). Sesuai dengan pasal 1553 KUHPerdata yang menyebutkan bahwa bila

\footnotetext{
${ }^{4}$ Kezia Damayanti Aron, 2018, “ Tanggung Gugat Debitur Atas Fidusia Dalam Bentuk Benda Persediaan Dan Keterkaitannya Dengan Akta Jaminan Fidusia”, Jurnal Magister Hukum Udayana, vol. 6, no. 3, Januari 2018, h. 359 https://ojs.unud.ac.id/index.php/jmhu/article/view/36115 diakses tanggal 18 Februari 2019 pukul 10.37 . 767

${ }^{5}$ Tim Penyusun Kamus Pusat Bahasa, 2005, Kamus Besar Bahasa Indonesia, Balai Pusaka, Jakarta, h.
} 
musnah suatu benda terjadi selama perjanjian itu berlangsung yang diakibatkan oleh suatu keadaan yang tidak bisa dipertanggungjawabkan pada salah satu pihak maka perjanjian sewa-menyewa dengan sendirinya batal. Jika barang menjadi barang tersebut jaminan dari perjanjian tersebut musnahnya diakibatkan oleh peristiwa yang tidak disengaja oleh pihak yang bersangkutan, jadi perjanjian yang di buat sebelumnya akan gugur demi hukum.

b) Musnah Sebagian. Barang yang menjadi obyek perjanjian kredit akan musnahnya sebagian maka obyek itu masih dapat digunakan dan dinikmati kegunaannya bila bagian dari barang yang menjadi obyek tersebut telah musnah. Jika barang yang menjadi obyek dari perjanjian kredit ini musnah sebagian, maka penyewa atau debitur akan mempunyai pilihan meneruskan perjanjian kredit dengan cara meminta pengurangan harga dari barang yang menjadi obyek jaminan tersebut atau dengan cara meminta pembatalan dari perjanjian kredit jika kedua pihak setuju.

Perlindungan terhadap kreditur diatur dalam KUHPerdata Pasal 1131 yang menyatakan bahwa segala barang-barang bergerak dan tidak bergerak milik debitur, baik yang sudah ada maupun yang akan ada, menjadi jaminan untuk perikatan-perikatan perorangan debitur itu. dan menurut Pasal 1132 KUHPerdata menyatakan bahwa harta kekayaan debitur menjadi jaminan secara bersamasama bagi semua kreditur yang memberikan kepadanya. Sedangkan berdasarkan Undang-Undang Nomor 42 Tahun 1999 Tentang Jaminan Fidusia, perlindungan hukum untuk 
pihak bank, didalam perjanjian dengan cara mempergunakan jaminan/angunan sangat diperlukan, dikarena obyek yang menjadi jaminan ada di tangan calon nasabah selaku pemberi fidusia.

Jika calon wanprestasi terhadap perjanjian yang telah disepakati sebelumnya, maka kepentingan dari pihak bank dapat dijamin dengan adanya perjanjian kredit dan perjanjian jaminan fidusia. Perlindungan hukum terbagi atas 2 suku kata yaitu perlindungan dan hukum. Perlindungan merupakan hal atau perbuatan untuk melindungai. Sedangkan menurut Wirjono Prodjodikoro hukum merupakan aturan untuk menjaga kepentingan semua pihak. ${ }^{6}$

Perlindungan hukum terhadap pihak bank didasarkan atas Undang-Undang Nomor 42 Tahun 1999 Tentang Jaminan Fidusia akan diberikan perlindungan tersebut terhadap kreditur apabila akta dari jaminan fidusia yang telah ditandatangani oleh pihak bank maupun pihak debitur yang dimana hal ini telah didaftarkan sebelumnya.

Kekuatan hukum Undang-Undang Nomor 42 Tahun 1999 Tentang Jaminan Fidusia ini bertujuan untuk menjamin dan melindungi hak-hak dari pihak bank selaku pemegang sertifikat jaminan fidusia, hal ini dilindungi secara hukum setelah pendaftaran tersebut dilaksanakan oleh bank selaku kreditur.

Bentuk dari perlindungan ini bagi pihak kreditur berdasarkaan Undang-Undang Nomor 42 Tahun 1999 Tentang Jaminan Fidusia yaitu : adanya perlindungan hukum bagi pembuatan perjanjian dan perjanjian jaminan fidusia yang dimana dibuat secara autentik di hadapan notaris

${ }^{6}$ Wirjono Prodjodikoro,1986, Asas-Asas Hukum Perjanjian, Bandung, h. 20. 
selaku pejabat yang berwenang di dalam hal ini didalam hal ini terdapat dalam Pasal 5 Undang-Undang Nomor 42 Tahun 1999 Tentang jaminan Fidusia.

Terdapat kantor pendaftaran jaminan fidusia, tujuannya untuk menjamin kepentingan dari para pihak yang menerima fidusia tersebut yang terdapat dalam Pasal 13 ayat 3 UndangUndang Nomor 42 Tahun 1999 Tentang Jaminan Fidusia. Terdapat larangan bagi nasabah yang memfidusiakan ulang obyek jaminan fidusia yang diatur dalam Pasal 17 UndagUndang Nomor 42 Tahun 1999 Tentang Jaminan Fidusia.

Kepentingan manusia merupakan sesuatu yang harus dilindungain oleh hukum, karena memang hukum itu dibuat oleh dan untuk manusia atau masyarakat. ${ }^{7}$

Terdapat aturan tentang pengaturan mengenai nasabah yang tidak diperbolehkan untuk melakukan pengalihan, penggadaikan dan/atau melakukan penyewaan yang ada didalam Pasal 23 ayat 2 Undang-Undang Nomor 42 Tahun 1999 Tentang Jaminan Fidusia. Adanya ketentuan bahwa kreditur penerima fidusia mendapatkan hak istimewa atau di dahulukan atas pelunasan hutang-hutang debitur kepada kreditur penerima fidusia yang terdapat dalam Pasal 27 Undang-Undang Nomor 42 Tahun 1999 Tentang Jaminan Fidusia.

Terdapat aturan mengenai nasabah yang wajib untuk menyerahkan benda yang akan di jaminan, kalau kreditur hendak melaksanakan eksekusi atas obyek jaminan yang ada didalam Pasal 30 Undang-Undang Nomor 42 Tahun 1999 Tentang Jaminan Fidusia. Adanya ketentuan pidananya

\footnotetext{
${ }^{7}$ Novitasari, 2017, “Tinjauan Yuridis Pembatasan Jangka Waktu Penundaan Kewajiban Pembayaran Utang Terhadap Debitor", Kertha Patrika, vol. 39, no. 2, Desember 2017, h. 102, https://ojs.unud.ac.id/index.php/kerthapatrika/article/view/35747 diakses tanggal 18 Februari 2019 pukul 11.26.
} 
terdapat di dalam Pasal 35 Undang-Undang Nomor 42 Tahun 1999 Tentang Jaminan Fidusia dan di dalam Pasal 36 Undang-Undang Nomor 42 Tahun 1999 Tentang Jaminan Fidusia.

\subsubsection{Upaya Yang Dapat Dilakukan Oleh Kreditur Penerim Fidusia Untuk Pelunasan Piutang Akibat Musnahnya Benda Yang Menjadi Obyek Jaminan}

Perjanjian pada dasarnya akan menimbulkan kewajiban bagi para pihak untuk memenuhi prestasi. Bila debitur tidak memenuhi kewajiban yang telah disepakati dalam perjanjian maka debitur disebut wanprestasi, tidak dipenuhinya kewajiban oleh debitur karena dua kemungkinan alasan yaitu karena kesalahan debitur atau karena keadaan memaksa (force majeure). ${ }^{8}$

Upaya yang dilakukan oleh pihak bank disini apabila obyek jaminan tersebut musnah maka akan dilakukan cara yang efektif yang akan dilakukan untuk mencegah kerugian yang akan timbul kemudian hari dengan cara pengalihan resiko, jika risiko atau peristiwa yang menyebabkan barang tersebut musnah maka pihak tersebut bersedia menanggung peralihan risiko tersebut kepada pihak ketiga selaku perusahaan asuransi. Debitur tetap mengembalikan pinjaman kredit kepada kreditur sebagai pertanggung jawaban atas jaminan dari benda bergerak yang hilang, dan debitur dapat melakukan pembaharuan utang (kompen).

Bila benda bergerak yang diasuransikan sudah diasuransikan tersebut hilang maka debitur yang bersangkutan akan tetap mempertanggungjawabkan pengembalian pinjaman kredit melalui perusahaan asuransi

${ }^{8}$ Abdulkadir Muhammad, 2010, Hukum Perdata Indonesia, PT. Citra Aditya Bakti, Bandung, h. 241. 
kepada kreditur, walaupun tidak dibayar sepenuhnya oleh perusahaan asuransi dimana benda jaminan diasuransikan dan sisa dari pinjaman krediit yang belum lunas tetap dilunasi oleh pihak debitur.

Tetapi jika benda jaminan bergerak tidak diasuransikan ternyata musnah maka debitur bertanggung jawab penuh dalam pengembalian pinjaman kredit kepada kreditur, dikarenakan debitur telah terikat dalam perjanjian kredit dengan pihak kredit. Hal ini sesuai dengan Pasal 24 UndangUndang Nomor 42 Tahun 1999 tentang Jaminan Fidusia. Apabila benda yang menjadi obyek jaminan itu musnah dikarenakan kesengajaan yang dilakukan oleh debitur maka pihak kreditur dapat menuntut pergantian atas benda jaminan dengan nilai jaminan yang sama, namun apabila dari pihak debitur tidak merespon atau menanggapi, maka pihak kreditur dapat menempuh jalur hukum dengan cara litigasi maupun no litigasi.

\section{PENUTUP}

\subsection{Kesimpulan}

1. Perlindungan kreditur atas musnahnya benda yang menjadi objek dari jaminan kreditur berhak menuntut ganti kerugian kepada debitur dan kreditur disini memiliki hak didalam menuntut perusahaan asuransi untuk mencairkan asuransi yang sebelumnya disepakati untuk menutup kerugian yang muncul karena objek jaminan fidusia yang musnah akibat kesalahan debitur sesuai dengan ketentuan yang terdapat di dalam polis asuransi untuk kepentingan kreditur 
2. Upaya yang dilakukan oleh kreditur dengan cara pembaruan utang dengan mengganti utang lama dengan utang baru, yang diganti disini perjanjian kreditnya dengan perjanjian kredit baru. Apabila musnah benda yang menjadi objek jaminan karena kesengajaan yang dilakukan debitur maka kreditur dapat menuntut pergantian benda jaminan dengan nilai jaminan yang sama, namun apabila dari pihak debitur tidak merespon atau menanggapi, maka pihak kreditur dapat menempuh jalur hukum dengan cara litigasi maupun no litigasi.

\subsection{Saran}

1. Diharapkan pemerintah untuk memperbaharui Undang-Undang Nomor 42 Tahun 1999 Tentang Jaminan Fidusia agar diberikanya aturan yang dapat memberikan penyelesaian secara menyeluruh terhadap pihak yang melakukan wanprestasi terhadap musnahnya benda yang menjadi obyek jaminan fidusia.

2. Dalam upaya yang dapat dilakukan oleh kreditur untuk pelunasan piutang akibat musnahnya benda yang menjadi obyek jaminan diharapkan pemerintah untuk memperbaharui Undang-Undang Nomor 42 Tahun 1999 Tentang Jaminan Fidusia agar diberikannya aturan yang dapat memberikan penyelesaian secara menyeluruh terhadap jaminan fidusia sesuai atas perjanjian kredit yang telah disepakati sebelumnya. 


\section{DAFTAR PUSTAKA}

\section{Buku}

Abdulkadir Muhammad, 2010, Hukum Perdata Indonesia, PT. Citra Aditya Bakti, Bandung.

Munir Fuady, 2003, Jaminan Fidusia, Citra Aditya Bakti, Cetakan ke-2 Revisi, Bandung.

O.P. Simorangkir, 1998, Seluk Beluk Bank Komersial, Aksara Persada Indonesia, Jakarta.

Philipus M.Hadjon, Tatiek Sri Djatmiati, 2005, Argumentasi Hukum, Gajah Mada University Press, Yogyakarta.

Prodjodikoro Wirjono, 1986, Asas-Asas Hukum Perjanjian, Bandung.

Tim Penyusun Kamus Pusat Bahasa Tim, 2005, Kamus Besar Bahasa Indonesia, Balai Pusaka, Jakarta.

Wirjono Prodjodikoro, 1986, Asas-Asas Hukum Perjanjian, Bandung.

\section{Peraturan Perundang-Undangan}

Kitab Undang-Undang Hukum Perdata (Burgerlijk Wetboek), 2009, diterjemahkan oleh R.Subekti dan R. Tjitrosudibio, Balai Pustaka, Jakarta.

Indonesia, Undang-Undang Republik Indonesia Tentang Perubahan Atas Undang-Undang Nomor 7 Tahun 1992 Tetang Perbankan, Undang-Undang Nomor 10 Tahun 1998, Lembaran Negara Republik Indonesia Tahun 1998 Nomor 182, Tambahan Lembaran Negara Republik Indonesia Nomor 3790.

Indonesia, Undang-Undang Republik Indonesia Tentang Jaminan Fidusia, Undang-Undang Nomor 42 Tahun 1999, Lembaran Negara Republik Indonesia Tahun 1999 Nomor 168, Tambahan Lembaran Negara Republik Indonesia Nomor 3889. 


\section{Jurnal Udayana.}

Kezia Damayanti Aron, 2018, "Tanggung Gugat Debitur Atas Fidusia Dalam Bentuk Benda Persediaan Dan Keterkaitannya Dengan Akta Jaminan Fidusia", Jurnal Magister Hukum Udayana, vol. 6, no. 3, Januari 2018, h.

https://ojs.unud.ac.id/index.php/jmhu/article/view/3 $\underline{6115}$ diakses tanggal 18 Februari 2019 pukul 10.37.

Novitasari, 2017, “Tinjauan Yuridis Pembatasan Jangka Waktu Penundaan Kewajiban Pembayaran Utang Terhadap Debitor", Kertha Patrika, vol. 39, no. 2, Desember 2017, h. 102, https://ojs.unud.ac.id/index.php/kerthapatrika/article /view/35747 diakses tanggal 18 Februari 2019 pukul 11.26 